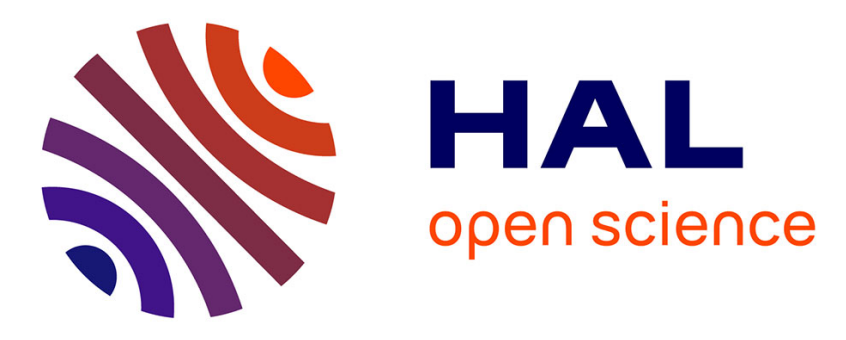

\title{
Perfluorocarbon-loaded lipid nanocapsules as oxygen sensors for tumor tissue $\mathrm{pO}(2)$ assessment.
}

Laurent Lemaire, Guillaume Bastiat, Florence Franconi, Nolwenn Lautram, Than Duong Thi Dan, Emmanuel Garcion, Patrick Saulnier, Jean-Pierre Benoit

\section{To cite this version:}

Laurent Lemaire, Guillaume Bastiat, Florence Franconi, Nolwenn Lautram, Than Duong Thi Dan, et al.. Perfluorocarbon-loaded lipid nanocapsules as oxygen sensors for tumor tissue pO(2) assessment.: Fluorinated lipid nanocapsules as oxygen sensor. European Journal of Pharmaceutics and Biopharmaceutics, 2013, epub ahead of print. 10.1016/j.ejpb.2013.01.003 . inserm-00785263

\section{HAL Id: inserm-00785263 https://www.hal.inserm.fr/inserm-00785263}

Submitted on 5 Feb 2013

HAL is a multi-disciplinary open access archive for the deposit and dissemination of scientific research documents, whether they are published or not. The documents may come from teaching and research institutions in France or abroad, or from public or private research centers.
L'archive ouverte pluridisciplinaire HAL, est destinée au dépôt et à la diffusion de documents scientifiques de niveau recherche, publiés ou non, émanant des établissements d'enseignement et de recherche français ou étrangers, des laboratoires publics ou privés. 
PERFLUOROCARBON-LOADED LIPID NANOCAPSULES AS OXYGEN SENSORS

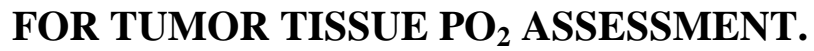

L. Lemaire ${ }^{1,2}$, G. Bastiat ${ }^{1,2}$, F. Franconi ${ }^{3}$, N. Lautram ${ }^{1,2}$, T. Duong Thi Dan ${ }^{1,2}$, E. Garcion ${ }^{1,}$ ${ }^{2}$, P. Saulnier ${ }^{1,2}$, and JP Benoit ${ }^{1,2}$.

Short title: Fluorinated lipid nanocapsules as oxygen sensor.

${ }^{1}$ INSERM U 1066, 'Micro et Nanomédecines biomimétiques - MINT', Angers, F-49933 France.

${ }^{2}$ LUNAM Université, Université Angers, UMR-S1066 Angers, F-49933 France.

${ }^{3}$ LUNAM Université, CIFAB-PRIMEX, Université d'Angers, F-49933 France.

Correspondence to:

Dr Laurent Lemaire

INSERM U 1066

Micro et Nanomédecines biomimétiques - MINT

IBS - CHU

4, rue Larrey

49933 Angers, France.

Tel.: $\quad$ (33) 0244688530

Fax.: $\quad$ (33) 0241735845

E-mail: $\quad$ laurent.lemaire@univ-angers.fr 


\section{ABSTRACT}

The assessment of tumor oxygenation is a crucial factor in cancer therapy and may be carried out using fluorine MRI once fluorine probes have been distributed within the tumor. However, the deposit of those highly fluorinated compounds often jeopardizes anatomical image quality and requires emulsification of the probes. Due to the high density and the high lipophilicity of perfluorocarbons, nanoemulsion of these molecules usually requires high energy processes. In the present work, we discuss the synthesis and the physico-chemical characterization of perfluorocarbon nanocapsules using a low-energy phase-inversion process. The nanocapsules were tested on a mouse tumor brain model to assess oxygenation.

\section{KEYWORDS}

Lipid nanocapsules; 19F-MRI; Fluorocarbon; Oxygenation; tumor.

\section{INTRODUCTION}

Hypoxia is a characteristic feature of locally-advanced solid tumors resulting from an imbalance between oxygen supply and consumption[1] . Hypoxia has been shown to play a key role in tumor resistance to radiation therapy[2] and also in decreasing the efficacy of certain cytotoxic drugs[3]. Numerous studies have demonstrated that tumor hypoxia, in addition to diminishing therapeutic efficacy, plays a major role in malignant progression [4].

Methods to determine tumor oxygenation are therefore of crucial importance for the prediction of therapeutic outcomes. Many current methods, such as Eppendorf electrodes[5], near-infrared spectroscopy[6], electron paramagnetic resonance imaging [7], susceptibility magnetic resonance imaging based methods[8] or ${ }^{19} \mathrm{~F}$ magnetic resonance imaging oximetry $[6,9]$ have been used in preclinical studies but have either been highly invasive, nonquantitative, or have lacked spatial resolution. As far as clinically available devices are concerned, MR-based techniques may be of interest, whereby, proton-based-imaging can be 
used to access blood oxygen change using the BOLD (Blood Oxygen Level-Dependent) sequence[8], currently widely used in clinics for functional magnetic resonance imaging (fMRI) studies. Nevertheless, this imaging technique is based on relaxivity changes that allow the depiction of oxygenation variations, but it does not enable the quantitative assessment of oxygen concentration [10]. However, recent studies have shown a high correlation between oxygen changes assessed using BOLD-imaging and oxygen levels measured using ${ }^{19} \mathrm{~F}-\mathrm{MRI}$ of a fluorinated oxygen probe in a preclinical model [11].

Currently, the major limitations of ${ }^{19} \mathrm{~F}$-oximetry is the lack of equipment of clinical MR to perform fluorine imaging. However, such a limitation can easily be removed since it only requires the acquisition of a specific ${ }^{19} \mathrm{~F}$-tuned probe. Fluorine oximetry is based on the influence of oxygen tension on the relaxivity of certain fluorinated probes. In the early 80's Clark et al. [12] showed a linear relation between longitudinal relaxivity of fluorinated probes with oxygen tension; this opened the field for MR oximetry [13-15]. Numerous fluorine probes were tested as oxygen sensors and numerous protocols have been proposed to optimize the injection of the fluorinated probes. Zhao et al. proposed a multiple deposit of the probe along 3 orthogonal directions in order to ensure that the interrogated regions are representative of the whole tumor [16]. However, as reported by these authors [11], the deposit induced signal voids on the anatomical proton images that can jeopardize the information that can be extracted from the anatomical data set.

To overcome this drawback, we propose the development of lipid nanocapsules to carry the fluorinated probe. Lipid nanocapsules are engineered using FDA-approved constituents (i.e. Solutol and Lipoid) that are prepared by a solvent-free and low -energy process[17], they are able to deliver drugs to a target[18] and, amazingly, they are characterized by an intrinsic effect on Multi-Drug-Resistance via the inhibition of P-gp [19]. According to the preparation process used, this nano-scaled platform can encapsulate 
hydrophilic[20] and lipophilic[21] compounds and therefore can encapsulate the lipophilic fluorinated $\mathrm{O}_{2}$ probe, the perfluoro-15-crown-5-ether $\left(\mathrm{C}_{10} \mathrm{~F}_{20} \mathrm{O}_{5}\right)$ in this case. This compound was chosen since all twenty fluorines are MR equivalent and therefore provide a single and intense resonance [22]. The second advantage of lipid nanocapsules is that they can be efficiently and homogeneously infused in tumors using the convection-enhanced delivery (CED) technique[23], a technique initially introduced in the early 90's[24] to deliver macromolecules to the brain but which is nowadays used in clinics to improve tumor therapy[25].

\section{EXPERIMENTAL}

\subsection{Materials}

Lipoïd $^{\circledR} \quad$ S75-3 (soybean lecithin - 69\% phosphatidylcholine and $10 \%$ phosphatidylethanolamine) and Solutol $^{\circledR}$ HS15 were supplied by Lipoïd GmbH (Ludwigshafen, Germany) and BASF (Ludwigshafen, Germany), respectively. Perfluoro-15crown-5-ether $\left(\mathrm{C}_{10} \mathrm{~F}_{20} \mathrm{O}_{5}\right)$ was provided by Chemos $\mathrm{GmbH}$ (Regenstauf, Germany). $\mathrm{NaCl}$ was purchased from Prolabo (Fontenay-sous-bois, France). Deionized water was obtained from a Milli-Q plus ${ }^{\circledR}$ system (Millipore, Bilerica, USA). $\mathrm{I}_{2}$ and KI were supplied by Sigma Aldrich Chemie GmbH (Steinheim, Germany). The abbreviations Lipoïd, Solutol, PEG, PEG-HS and PFCE are used for Lipoïd ${ }^{\circledR}$ S75-3, Solutol ${ }^{\circledR}$ HS15, polyethylene glycol, polyethylene glycol hydroxystearate, and perfluoro-15-crown-5-ether, respectively.

\section{$\underline{\text { 2.2. Formulation process }}$}

The quantities of PFCE (oil phase), water and $\mathrm{NaCl}$ (aqueous phase), Solutol ${ }^{\circledR}$ HS15 and Lipoïd (surfactants) were precisely weighed: $\mathrm{m}_{\mathrm{PFCE}}=2 \mathrm{~g}, \mathrm{~m}_{\text {Solutol }}=0.846 \mathrm{~g}, \mathrm{~m}_{\text {Lipoïd }}=0.075 \mathrm{~g}$, $\mathrm{m}_{\mathrm{Water}}=2 \mathrm{~g}$ and $\mathrm{m}_{\mathrm{NaCl}}=0.1 \mathrm{~g}$. A four step process was tested to obtain PFCE nanocapsules (PFCE-LNC). After an increase of temperature from room temperature to $95^{\circ} \mathrm{C}$ to dissolve the 
Lipoïd, a 1 min-sonication of the mixture with the power of 3, 5 or $10 \mathrm{~W}$ using a Microson XL2007 (Misonix, Farmingdale, USA) sonication probe was performed prior to three heating and cooling cycles from $25^{\circ} \mathrm{C}$ to $95^{\circ} \mathrm{C}$. During the final cooling, when the temperature reaches $70^{\circ} \mathrm{C}$, a rapid cold dilution was performed by adding 3.5 volumes of cold milli-Q water.

The influence of the formulation composition on PFCE-LNC synthesis was assessed when the process used included the 1 minute sonication period at 10W. PFCE, Solutol, Lipoïd, NaCl and deionized water, were weighed to obtain a final mixture (about 5g), with PFCE composition from 0.10 to $0.55 \mathrm{w} / w_{\text {Total }}$, Solutol composition from 0.05 to $0.35 \mathrm{w} / \mathrm{w}_{\text {Total }}$, deionized water composition form 0.25 to $0.80 w / w_{\text {Total }}$. $\mathrm{m}_{\text {Lipoid }}$ and the $\mathrm{NaCl}$ concentration was fixed at $0.075 \mathrm{~g}$ and $5 \% \mathrm{w} / \mathrm{w}_{\text {water }}$.

These different formulations were stored at $4^{\circ} \mathrm{C}$ and size stability over the experimental time was assessed.

\subsection{Physico-chemical characterization of PFCE-LNCs}

\subsubsection{Size measurement.}

The average hydrodynamic diameter Z-average (Z-ave) and the polydispersity index (PdI) of PFCE-LNC were determined by dynamic light scattering using a Malvern Zetasizer ${ }^{\circledR}$ (Nano Series DTS 1060, Malvern Instruments S.A., Worcestershire, UK) fitted with a $633 \mathrm{~nm}$ laser beam (helium-neon laser, $4 \mathrm{~mW}$ ) at a fixed scattered angle of $173^{\circ}$. Measurements were made at $25^{\circ} \mathrm{C}$, with $0.89 \mathrm{cP}$ viscosity and a refractive index of 1.33 . The autocorrelation function was fitted using the cumulant analysis method to obtain Z-ave and PdI values. The PFCELNCs were diluted with pure water (dilution factor: 60) before size measurement; each measurement was performed three times.

\subsubsection{Interface characterization - Drop tensiometer.}


Adsorption kinetics measurements were carried out at the oil-water interface by means of a pendant drop method[26] (Tracker, IT Concept, Longessaigne, France). A drop was formed with an Exmire microsyringe (Prolabo, Paris, France) into an optical glass cell (Hellma, Paris, France) containing the other phase. In our case, a pendant drop of PFCE was formed in aqueous solution containing Solutol at various concentrations (from 0 to $400 \mathrm{mg} . \mathrm{L}^{-1}$ ). The cell was maintained at room temperature. The axial symmetric shape (Laplacian profile) of the drop was analyzed using a video camera connected to a computer. In this study, the volume of the drop was $5 \mu \mathrm{L}$ and the Laplacian shape of the drop was always checked. From the analysis of the numerical image of the drop using the Laplace equation and integrating the points of the drop profile, the interfacial tension, interfacial area and volume of the drop were derived in real time (five measurements per second). The experiment was stopped once the interfacial tension remained constant for 30 minutes.

\subsubsection{Electrophoretic measurements.}

Dialysis of PFCE-LNC (5 mL) was performed (Spectra/Por ${ }^{\circledR}$ Biotech Cellulose Ester Dialysis Membrane, $\mathrm{MWCO}=50 \mathrm{kDa}$ ) for one week against pure water (obtained through a milli-Q apparatus, Millipore, Saint Quentin en Yvelines, France), changing the water twice a day. At the end of dialysis and after size verification (similar to hydrodynamic diameter as before dialysis), the PFCE-LNCs were diluted with saline (dilution factors: 60, 600 and 6,000) to obtain different ionic strengths (from 2.5 to $50 \mathrm{mM}$ ). An electrophoretic mobility test was performed using a Malvern Zetasizer ${ }^{\circledR}$ (Nano Series DTS 1060). Three different PFCE-LNC batches were prepared to obtain the mean value of electrophoretic mobility \pm standard deviation (SD) vs. $\mathrm{NaCl}$ concentrations.

The surface properties of the nanoparticles were studied by soft-particle analysis using the Ohshima theory $[27,28]$. Ohshima showed that the electrophoresis mobility of a soft particle 
depended on the volume charge density distributed in the polyelectrolyte layer, on the frictional forces exerted by the polymer segments on the liquid flow in the polyelectrolyte layer, on the particle size, and on the frequency of the applied oscillating electric field. The theoretical curve (Eq. 1) represents the dependence of electrophoretic mobility ( $\mu$ ) as a function of the charge number density (n), used to evaluate $\mathrm{Km}$, the Debye-Hückel parameter of the shell, $\kappa$, the reciprocal of the Debye length, $\Psi_{\mathrm{DON}}$, the Donnan potential (unequal distribution of diffusible ions between two ionic solutions) and $\Psi_{0}$, the potential at the boundary between the surface region and the solution:

$$
\mu=\frac{\varepsilon_{0} \varepsilon_{\mathrm{r}}}{\eta} \frac{\frac{\Psi_{0}}{\mathrm{Km}}+\frac{\Psi_{\mathrm{DON}}}{\lambda}}{\frac{1}{\mathrm{Km}}+\frac{1}{\lambda}} \frac{\mathrm{e} \mathrm{ZN}}{\eta \lambda^{2}}
$$

Eq. 1

where $\eta$ is the viscosity of the medium expressed in $\mathrm{Pa}^{-1}{ }^{-1}, \varepsilon_{\mathrm{r}}=80$ (relative permittivity of the electrolyte solution), $\varepsilon_{0}=8.85 .10^{-23} \mathrm{~J}^{-\mathrm{K}^{-1}}$, e $=1.6 .10^{-19} \mathrm{C}$ (elementary electric charge), $\mathrm{T}$ is the thermodynamic absolute temperature, $\mathrm{k}$ is the Boltzmann constant and $\mathrm{n}$ is the bulk concentration of the electrolyte solution, expressed in C. $\mathrm{m}^{-3}$.

This method allows the calculation of $\mathrm{ZN}$ and $\lambda$ which characterize the electric properties of the surface of particles; $\mathrm{ZN}$ represents the spatial charge density in the polyelectrolyte region and $\lambda$ is a physical constant characterizing the degree of resistance to liquid flow in the polyelectrolyte region. The reciprocal of $\lambda$, which is $1 / \lambda$, has the dimension of length and can be regarded as the "softness" parameter of the NP surface. All electrophoretic mobilitiy and softness values reported were the mean of three measurements with separately prepared batches.

\subsubsection{Polyethylene glycol titration.}


The dialysis of PFCE-LNCs $(5 \mathrm{~mL})$ was performed (Spectra/Por ${ }^{\circledR}$ Biotech Cellulose Ester Dialysis Membrane, MWCO $=50 \mathrm{kDa}$ ) against $100 \mathrm{~mL}$ of pure water (obtained through a milli-Q apparatus, Millipore, Saint Quentin en Yvelines France) at room temperature under magnetic stirring, to remove PEG chains (from Solutol) not associated to PFCE-LNC. The PEG concentration was determined by the use of a colorimetric method, based on the complex formation between PEG and iodine [29]. $100 \mu \mathrm{L}$ aliquots were collected $v s$. time (from 0 to 120-h) in the dialysis external medium and immediately replaced with $100 \mu \mathrm{L}$ of pure water. To this $100-\mu \mathrm{L}$ aliquot was added $25 \mu \mathrm{L}$ of $\mathrm{KI} / \mathrm{I}_{2}\left(0.01\right.$ and $0.02-\mathrm{g} \cdot \mathrm{mL}^{-1}$ for $\mathrm{I}_{2}$ and $\mathrm{KI}$, respectively), and absorbance was measured at $492 \mathrm{~nm}, 5$ minutes after the addition. The calibration curve was assessed using Solutol solutions. Experiments were performed in triplicate.

\section{$\underline{\text { 2.4. Magnetic resonance imaging protocols }}$}

\subsubsection{In vitro studies}

The in vitro calibration relating the $\mathrm{R}_{1}$ of perfluoro 15 -crown-5 ether encapsulated in lipid nanocapsules to the $\mathrm{O}_{2}$ partial pressure value were made using three different $\mathrm{O}_{2}$ concentrations $(0,21$ and $100 \%$ corresponding to 0,160 and $760 \mathrm{mmHg}$, respectively) with balance $\mathrm{N}_{2}$. The colloidal suspension was bubbled for 30 minutes to equilibrium at $37^{\circ} \mathrm{C} .{ }^{19} \mathrm{~F}$ measurements were performed on a Bruker Biospec 70/20 operation at a magnetic field of $7 \mathrm{~T}$ (Bruker, Wissembourg, France). The resonant circuit of the NMR probe was a 40-mm diameter, double tuned $\left({ }^{1} \mathrm{H} /{ }^{19} \mathrm{~F}\right)$ birdcage. The sequence used was a multi-spin echo sequence $($ RARE factor $=8$, mean TE $=21.7 \mathrm{~ms})$ with multiple TR $(300 \mathrm{~ms}, 800 \mathrm{~ms}, 1,500 \mathrm{~ms}$ and 6,000ms). 4 averages were performed. The geometrical parameters were fixed at FOV = $2 \times 2 \mathrm{~cm}$, matrix $64 \times 64$, slice thickness $=4 \mathrm{~mm}$. Using Equation 2: 


$$
\frac{1}{T 1}=A+S^{*} p O 2 \quad(\text { Eq. } 2)
$$

The average T1 value of the 3 measurements per oxygen concentration was used for the linear fit of 1/T1 vs. pO2, from which the anoxic intercept $\mathrm{A}$ and slope $\mathrm{S}$ were derived.

\subsubsection{In vivo studies}

\subsubsection{Tumor induction}

Animal care and use were in strict accordance with the regulations of the French Ministry of Agriculture. Brain tumors were induced by stereotaxic inoculation of glioma cells as previously described [30]. Briefly, 7-8week-old male SCID mice (Charles Rivers, France) were anesthetized with a mixture of Rompun ${ }^{\circledR}$ (Xylazine, Bayer AG, Leverkusen, Germany) and Clorketam ${ }^{\circledR}$ (Kétamine, Vétoquinol, Lure, France) before being fixed in a stereotaxic holder. Through a small hole drilled in the skull (anterior $-0.5 \mathrm{~mm}$, lateral $2 \mathrm{~mm}$, depth $-3 \mathrm{~mm}$ according to the bregma), $5 \mu$ l of a suspension of 50,000 grade IV glioma cells were injected over a 10-minute time period into the caudate putamen of the right hemisphere [31].

\subsubsection{Tumor growth control and $\mathbf{p} \mathbf{O}_{2} \underline{\text { measurement }}$}

After 8-10 weeks, the animals were scanned using a Bruker Biospec 70/20 operating at a magnetic field of 7T (Bruker, Wissembourg, France) equipped with a ${ }^{1} \mathrm{H}$ cryoprobe under isoflurane anesthesia $\left(1.5-0.5 \%, \mathrm{O}_{2} 0.5 \mathrm{~L} / \mathrm{min}\right)$ to assess tumor development. Mice body temperature was maintained at $36.5-37.5^{\circ} \mathrm{C}$ by using a feedback-regulated heating pad during the entire imaging protocol. Rapid anatomical proton images were obtained using a rapid acquisition with relaxation enhancement (RARE) sequence ( $T R=3,200 \mathrm{~ms}$; mean echo time $(\mathrm{TEm})=21.3 \mathrm{~ms} ;$ RARE factor $=4$; FOV $=2 \times 2 \mathrm{~cm}$; matrix 256 $\times 256$; nine contiguous slices of $0.5 \mathrm{~mm}, \mathrm{Nex}=1)$. T1 weighting was introduced in these images by using an inversion pulse 
prior to the RARE pattern in order to better the depiction of the tumors. The duration of the inversion delay was fixed at $600 \mathrm{~ms}$, enough time to allow the annulation of the normal parenchyma [32]. When a tumor was detected, the mice underwent an intratumoral stereotactic injection of $8 \mu \mathrm{L}$ of the PFCE-LNCs using a convection-enhanced delivery protocol[33]. The fluorine acquisitions were performed immediately and could be repeated for at least a week using the same protocol as the one used for the in vitro study. The resonant circuit was a $40 \mathrm{~mm}{ }^{1} \mathrm{H} /{ }^{19} \mathrm{~F}$ coil, and the sequence used was the same as the one used for the in vitro studies.

\section{RESULTS AND DISCUSSION}

\subsection{PFCE-LNC formulation.}

The morphology of LNC results in an oily core surrounded by lecithins and a non-ionic surfactant [34]. The formulation protocol is based on a phase-inversion process due to the specific properties of the non-ionic surfactant, PEG-HS present in Solutol. Then, PEG-HS gives an oil-in-water emulsion $(\mathrm{O} / \mathrm{W})$ at room temperature and a water-in-oil emulsion $(\mathrm{W} / \mathrm{O})$ at high temperature [17].

This inversion process was tested to obtain PFCE nanocapsules (PFCE-LNC), using PFCE as the oil in the formulation. First of all, it appeared that the oil and water phases were not easy to mix due to the high density of PFCE $(\mathrm{d} \sim 2)$ and the size of the dispersed droplets produced were large (hydrodynamic diameter (Z-ave) 450nm) with a high polydispersity index (PdI $0.7)$.

In the literature, sonication in combination with high pressure is often used to obtain PFCELNCs [35, 36]. In our case, sonication at atmospheric pressure was used to improve the dispersion of the oil and water phases before the phase-inversion process. A first cycle of temperature was added before the sonication step to allow the Lipoïd to melt. Various sonication powers were tested $(0,3,5$ and $10 \mathrm{~W})$ prior to the phase-inversion process. Without 
sonication, no PFCE-LNCs were formulated. When the sonication power was increased, PFCE-LNCs were formulated with sizes ca. $300 \mathrm{~nm}$ when the power was set to $3 \mathrm{~W}$, and ca. $200 \mathrm{~nm}$ when the power was set to 5 or $10 \mathrm{~W}$. The higher sonication power led to a narrowing of the PFCE-LNC population ( $\mathrm{PdI}=0.14$ vs 0.22 for $10 \mathrm{~W}$ vs $5 \mathrm{~W})$.

As a consequence, the formulation process had to include four steps: i) temperature increase of the formulation from room temperature to $95^{\circ} \mathrm{C}$ to allow the Lipoïd melting; ii) sonication of the formulation to the power of $10-\mathrm{W}$ for 1 minute; iii) 3 temperature cycles from $25^{\circ} \mathrm{C}$ to $95^{\circ} \mathrm{C}$; iv) and finally, during the last temperature decrease, when the temperature reaches $70^{\circ} \mathrm{C}$, a rapid cold dilution with deionized water (dilution factor: 3.5 ).

The composition is however a crucial point for PFCE-LNC formulation using this low-energy process. Indeed, using Fan's formulation composition [35], i.e. PFCE 2g, Lipoïd 0.12g, glycerin $0.09 \mathrm{~g}$ and deionized water $2.91 \mathrm{~g}$, larger particles were obtained with a hydrodynamic diameter $(\mathrm{Z}$-ave $) \sim 250 \mathrm{~nm}$ and a higher polydispersity index $(\mathrm{PdI} \sim 0.25)$. Interestingly, those nanoparticles are however comparable in size with those obtained using the high-energy process described by Fan et al[35].

Therefore, with respect to the phase-inversion process and the composition used in this work, the phase diagram was explored changing the proportions of deionized water, Solutol and PFCE. The Lipoïd quantity remained constant at $0.075 \mathrm{~g}$ and the $\mathrm{NaCl}$ concentration was maintained at $5 \% w / w_{\text {Water }}$. Influences of lipoïd and $\mathrm{NaCl}$ on the formulation have been studied previously. Without Lipoïd, PFCE-LNCs were impossible to obtain and a rapid phase separation was observed. The addition of higher Lipoïd quantities led to PFCE-LNCs with larger sizes and larger PdIs. With $0.15 \mathrm{~g}$ and $0.3 \mathrm{~g}$ of Lipoïd, the Z-ave values were about 330nm $(\mathrm{PdI} \sim 0.7)$ and 220nm $(\mathrm{PdI} \sim 0.31)$, respectively. An increase in $\mathrm{NaCl}$ concentration did not change the size and PdI of PFCE-LNCs. At an NaCl concentration of $10 \% \mathrm{w} / w_{\text {Water }}$, the Z-ave was $197 \mathrm{~nm}$ and the PdI was 0.115 . Changing the temperature of the medium at 
which the rapid cold dilution occurred did not significantly change the PFCE-LNC parameters. Indeed, when temperatures were 50,60 and $90^{\circ} \mathrm{C}$, the $\mathrm{Z}$-ave values were 189,196 and $189-\mathrm{nm}$, respectively, and the PdI were $0.11,0.11$ and 0.10 , respectively.

The PFCE, Solutol and deionized water compositions ranged from 0.1 to $0.55 w / w_{\text {Total }}$, from 0.05 to $0.35 w / w_{\text {Total }}$ and from 0.25 to $0.80 w / w_{\text {Total }}$, respectively. The defined process was used for PFCE-LNC formulation and the results are reported on a phase diagram in Figure 1. A feasibility area was observed, corresponding to PFCE-LNCs with Z-ave $<200 \mathrm{~nm}$ and PdI $<0.2$. The limits of the domain were : about 0.1 to $0.2 w / w_{\text {Total }}$ for Solutol, about 0.2 to 0.45 $w / w_{\text {Total }}$ for PFCE and about 0.4 to $0.6 w / w_{\text {Total }}$ for deionized water. Outside this area, the PFCE-LNC size and the PdI were above $200 \mathrm{~nm}$ and 0.2 , respectively. Whatever the composition inside the feasibility area, a constant value of Z-ave was found, slightly lower than 200nm. For the system with a PFCE core, a size limit was observed while for LNCs with Labrafac core, size was dependent on the oil - surfactant ratio [37].

Figure 2 presents the stability of PFCE-LNC size as a function of time when stored at $4{ }^{\circ} \mathrm{C}$. According to the phase diagram, the formulation was performed using $0.168 w / w_{\text {Total }}$ for Solutol, $0.015 w / w_{\text {Total }}$ for Lipoïd, $0.02 w / w_{\text {Total }}$ for $\mathrm{NaCl}, 0.398 w / w_{\text {Total }}$ for PFCE and 0.398 $w / w_{\text {Total }}$ for deionized water. A slight increase in size and the PdI (about 10\%) was observed over a 3 month period of time. In addition, during storage and according to the high density of the oil, sedimentation of the PFCE-LNC was observed but a simple dispersion under stirring allows the material to be recovered without size modification. Interestingly, it should then be possible to concentrate the PFCE-LNCs using the property of sedimentation for these nanocarriers.

\subsection{PFCE-LNC characterization.}


PFCE-LNCs appeared to be different from classical Labrafac-LNCs, at least in terms of size dependency with respect to formulation composition. The density of the PFCE ( 2) may account for this observation but the interaction of the surfactant may also be peculiar with this oil. As a consequence, the amphiphilic properties of PEG-HS were carefully examined at a PFCE-water interface. A PFCE pendant drop was formed using a drop tensiometer in a water phase containing various concentrations of Solutol from 0 to $0.4 \mathrm{~g} \cdot \mathrm{L}^{-1}$. A significant decrease of the surface tension from 45 to $20 \mathrm{mN} . \mathrm{m}^{-1}$ was observed when Solutol concentrations were increased (Figure 3). PEG-HS from Solutol acted as a surfactant at the PFCE-water interface, as it was observed for with Labrafac oil[38]. This may then explain the feasibility of producing lipid nanocapsules with PFCE.

As PFCE-LNC size was larger than those reported for Labrafac-LNC, the quantity of PEGHS involved in nanoparticles was determined. PFCE-LNC formulation was dialyzed to remove all the free materials after formulation. The PEG chain concentration was obtained using $\mathrm{KI} / \mathrm{I}_{2}$ titration. As observed in Figure 4, about $20 \%(w / w)$ of PEG was free after the formation of the LNCs corresponding to the free PEG chains present in commercial Solutol. Therefore, PEG-HS from Solutol totally participated into the formation of nanoparticle shells. In order to appreciate the softness of PFCE-LNCs, Ohshima's model was applied[28]. This model was used to fit the experimental electrophoretic mobility of PFCE-LNCs, diluted by factors 60, 600 and 6,000, vs. $\mathrm{NaCl}$ concentrations (Figure 5 for the dilution factor 600). No difference for the experimental electrophoretic mobility was obtained, whatever the dilution of PFCE-LNCs, and the experimental data points were fitted using the Ohshima model showing that the PFCE-LNCs could be considered as a charged, hard sphere surrounded by a non-charged, soft-shell. The two fitting parameters were determined: $\mathrm{ZN}=-0.67 \pm 0.21 .10^{6}$ C. $\mathrm{m}^{-3}$ and $1 / \lambda=3.5 \pm 1.0 \mathrm{~nm}$. The second parameter corresponds to the ion penetration layer around the hard sphere. This penetration layer appeared to be significantly different from the 
one measured in Labrafac-LNC $(\sim 0.1 \mathrm{~nm})[39]$ and suggested that the organization within the PFCE-LNCs shell was unusual.

In order to characterize this peculiar organization of the HS-PEG at the interface PFCE-water in the PFCE-LNCs, the HS-PEG density was calculated. According to Minkov et al. [40], when HS-PEG molecules are perfectly and compactly organized at the Labrafac-water interface, the surface occupied by one molecule of surfactant is about $1 \mathrm{~nm}^{2}$. In PFCE-LNC, such a calculation was performed (Appendix 1) and showed that each HS-PEG molecule only occupied $0.1 \mathrm{~nm}^{2}$. This lower value and therefore higher density can only be reached with a chaotic arrangement of HS-PEG (Figure 6).

Thus, PFCE-LNC can be described as a PFCE spherical core surrounded by lipoïd and PEGHS whose organization at the interface oil-water is chaotic. The shell layer accessible to ions, calculated using the Ohshima model at $3.5 \mathrm{~nm}$, corresponded to the accessible depth inside this chaotic organization. As it currently is, the thickness of the shell is unknown but has to be above the thickness of the shell in labrafac-LNC. The thickness of the shell and its chaotic organization may then impede the diffusion of $\mathrm{O}_{2}$ molecules toward the fluorinated sensor, a compulsory phenomenon to assess $\mathrm{pO}_{2}$. In order to test this hypothesis, an assessment of relaxivity changes of the PFCE entrapped in the PFCE-LNC as a function of surrounding $\mathrm{pO}_{2}$ was performed.

\subsection{PFCE-LNC and MRI.}

\subsubsection{T1 Measurement of PFCE-loaded nanocapsules in vitro and relationship with $\mathrm{pO}_{2}$.}

First of all, a comparison between the sensitivity of free PFCE and of encapsulated PFCE with respect to oxygenation was performed. No significant changes were observed. Indeed, T1 measurements performed at $20^{\circ} \mathrm{C}$ lead to values of $2380 \mathrm{~ms}, 1300 \mathrm{~ms}$ and $582 \mathrm{~ms}$ for the free PFCE when the samples were exposed to $0 \%, 21 \%$ or $100 \%$ O2 and to values of $2296 \mathrm{~ms}$, $1397 \mathrm{~ms}$ and $607 \mathrm{~ms}$ for encapsulated PFCE. To characterize the sensitivity of the PFCE- 
LNCs to oxygenation, T1 values of the suspension of PFCE-loaded nanocapsules after bubbling for 30 min with $100 \% \mathrm{O}_{2}$, air $\left(21 \% \mathrm{O}_{2}\right)$ or $100 \% \mathrm{~N}_{2}$ were measured as a function of the suspension temperature. According to Figure 7 , at $37^{\circ} \mathrm{C}$, T1 values of $376 \pm 15 \mathrm{~ms}, 972 \pm$ $33 \mathrm{~ms}$ and $1,530 \pm 45 \mathrm{~ms}$ were measured after bubbling in $100 \% \mathrm{O}_{2}$, air $\left(21 \% \mathrm{O}_{2}\right)$ or $100 \% \mathrm{~N}_{2}$, respectively. The linear regression from $\mathrm{R} 1$ (defined as $1 / \mathrm{T} 1$ ) over $\mathrm{pO}_{2}$ (at $37^{\circ} \mathrm{C}$ ), yielded for the anoxic intercept $A$, the value $0.6582 \pm 0.026 \mathrm{~s}^{-1}$, and for the slope $S$, the value $0.0026 \pm$ $0.0001 \mathrm{~s}^{-1} \mathrm{mmHg}^{-1}$. The calculation of the $\mathrm{pO}_{2}$ value can then be performed using Equation 3 .

$$
\mathrm{pO}_{2}(m m H g)=\frac{[(1 / \mathrm{T} 1(\mathrm{~s}))-0.6582]}{0.0026} \quad(\text { Eq. 3) }
$$

Despite being limited, an effect of temperature is observed on 1/T1 value, which then interferes with the in vivo $\mathrm{pO}_{2}$ measurements. This error on $\mathrm{pO}_{2}$ measurements can be calculated from multiple linear regression analysis (Matlab R2011b) of the data presented in Figure 6 as Equation 4:

$$
\mathrm{R} 1\left(s^{-1}\right)=1.2063+0.025 \mathrm{pO}_{2}(m m H g)-0.144 T\left({ }^{\circ} \mathrm{C}\right) \mathrm{r}^{2}=0.9987 \quad \text { (Eq. 4) }
$$

Assuming a $\mathrm{T} 1$ value of $1,150 \mathrm{~ms}$, the $\mathrm{pO}_{2}$ value at 37,36 or $35^{\circ} \mathrm{C}$ is 78,73 or $67 \mathrm{mmHg}$. Despite this potential drawback in $\mathrm{pO}_{2}$ measurements, one may assume that in vivo, the temperature will be constant and therefore, that $\mathrm{pO}_{2}$ changes will reflect biochemical processes.

\subsection{2. $\mathrm{PO}_{2}$ measurement in vivo}

The stereotactic injection of $8 \mu \mathrm{L}$ of the PFCE-loaded nanocapsules suspension was sufficient to allow the detection of a significant fluorine signal (signal-to-noise ratio for $\mathrm{TR}=6,000 \mathrm{~ms}$ was about 20), that can be used to assess tumor $\mathrm{pO}_{2}$ (Figures $8 \mathrm{~A} \& 8 \mathrm{~B}$ ). On the images presented, when the mouse was anesthetized for 20 minutes using isoflurane vaporized with pure oxygen (Figure 8A), the tumor $\mathrm{pO}_{2}$ was calculated on three consecutive sets of images, assuming a tumor temperature of $37^{\circ} \mathrm{C}$, at 159,186 and $177 \mathrm{mmHg}$ leading to an average value of $174 \pm 14 \mathrm{mmHg}$. When the vaporizing gas was switched to air, the tumor $\mathrm{pO}_{2}$ 
dropped below $50 \mathrm{mmHg}$ within 10 minutes to tend to values below $10 \mathrm{mmHg}$ within 30 minutes in the presented primary grade IV brain tumor model (Figure $8 \mathrm{~B}$ ). As previously described, the profile of the $\mathrm{pO}_{2}$ change with time can be fitted with a monoexponential function whose time constant reflect mainly tumor oxygen consumption as perfusion has a limited effect $[9,41]$. In the type of tumor explored (Figure 8C), this time constant (k) was calculated at $\mathrm{k}=0.16 \mathrm{~min}^{-1}$. This measurement can be repeated over time for at least 10 days in this fast growing tumor model. Currently, the temporal resolution of the $\mathrm{pO}_{2}$ assessment is ca. 4min, and may be significantly reduced using the SNAP-IR sequence presented by Jordan [42] assuming that the achievable spatial resolution will be compatible with the small tumors present in the mouse brain. This figure also showed that despite the entrapment of the sensor within the nanocapsules, oxygen molecules can access the PFCE through the constituted surfactant shell.

\section{CONCLUSIONS}

Nanoscaled platform capable of measuring brain tumor $\mathrm{pO}_{2}$ using fluorine MRI was synthesized. Despite the high density and the high lipophilicity of the fluorinated $\mathrm{pO}_{2}$ sensor, i.e. perfluoro-15-crown-5-ether, the low-energy, phase-inversion process used to produce lipid nanocapsules could be implemented. The resulting nanocapsules are composed of a perfluoro15-crown-5-ether core surrounded by a chaotic arrangement of polyethylene glycol hydroxystearate that does not interfere with $\mathrm{O}_{2}$ molecule diffusion toward the oxygenation sensor. Once injected in brain tumors using a convection-enhanced delivery protocol, a $\mathrm{pO}_{2}$ map of the tumor can then be performed.

\section{ACKNOWLEDGEMENTS}


Authors acknowledge financial support from 'Comité Inter-Régional Grand Ouest de La Ligue Contre le Cancer' - CIRGO and 'La Ligue nationale contre le cancer - Equipe Labellisée 2012'. Authors would like to thank Dr. David Rees for editing the manuscript. 


\section{BIBLIOGRAPHY:}

[1] P. Vaupel, O. Thews, M. Hoeckel, Treatment resistance of solid tumors: role of hypoxia and anemia, Med Oncol, 18 (2001) 243-259.

[2] M. Nordsmark, M. Hoyer, J. Keller, O.S. Nielsen, O.M. Jensen, J. Overgaard, The relationship between tumor oxygenation and cell proliferation in human soft tissue sarcomas, Int J Radiat Oncol Biol Phys, 35 (1996) 701-708.

[3] K. Selvendiran, A. Bratasz, M.L. Kuppusamy, M.F. Tazi, B.K. Rivera, P. Kuppusamy, Hypoxia induces chemoresistance in ovarian cancer cells by activation of signal transducer and activator of transcription 3, Int J Cancer, 125 (2009) 2198-2204.

[4] M. Hockel, K. Schlenger, B. Aral, M. Mitze, U. Schaffer, P. Vaupel, Association between tumor hypoxia and malignant progression in advanced cancer of the uterine cervix, Cancer Res, 56 (1996) 4509-4515.

[5] M.C. Kavanagh, V. Tsang, S. Chow, C. Koch, D. Hedley, S. Minkin, R.P. Hill, A comparison in individual murine tumors of techniques for measuring oxygen levels, Int $\mathbf{J}$ Radiat Oncol Biol Phys, 44 (1999) 1137-1146.

[6] M. Xia, V. Kodibagkar, H. Liu, R.P. Mason, Tumour oxygen dynamics measured simultaneously by near-infrared spectroscopy and $19 \mathrm{~F}$ magnetic resonance imaging in rats, Phys Med Biol, 51 (2006) 45-60.

[7] G. Meenakshisundaram, E. Eteshola, R.P. Pandian, A. Bratasz, K. Selvendiran, S.C. Lee, M.C. Krishna, H.M. Swartz, P. Kuppusamy, Oxygen sensitivity and biocompatibility of an implantable paramagnetic probe for repeated measurements of tissue oxygenation, Biomed Microdevices, 11 (2009) 817-826.

[8] S. Ogawa, T.M. Lee, A.R. Kay, D.W. Tank, Brain magnetic resonance imaging with contrast dependent on blood oxygenation, Proc Natl Acad Sci U S A, 87 (1990) 9868-9872.

[9] C. Diepart, J. Magat, B.F. Jordan, B. Gallez, In vivo mapping of tumor oxygen consumption using (19)F MRI relaxometry, NMR in Biomedicine, 24 (2011) 458-463.

[10] C. Baudelet, B. Gallez, How does blood oxygen level-dependent (BOLD) contrast correlate with oxygen partial pressure $(\mathrm{pO}(2))$ inside tumors?, Magnet Reson Med, 48 (2002) 980-986.

[11] D. Zhao, L. Jiang, E.W. Hahn, R.P. Mason, Comparison of 1H blood oxygen leveldependent (BOLD) and 19F MRI to investigate tumor oxygenation, Magn Reson Med, 62 (2009) 357-364.

[12] L.C. Clark, Jr., J.L. Ackerman, S.R. Thomas, R.W. Millard, R.E. Hoffman, R.G. Pratt, H. Ragle-Cole, R.A. Kinsey, R. Janakiraman, Perfluorinated organic liquids and emulsions as biocompatible NMR imaging agents for 19F and dissolved oxygen, Adv Exp Med Biol, 180 (1984) 835-845.

[13] C.H. Sotak, P.S. Hees, H.N. Huang, M.H. Hung, C.G. Krespan, S. Raynolds, A new perfluorocarbon for use in fluorine-19 magnetic resonance imaging and spectroscopy, Magn Reson Med, 29 (1993) 188-195.

[14] R.P. Mason, P.P. Antich, E.E. Babcock, J.L. Gerberich, R.L. Nunnally, Perfluorocarbon imaging in vivo: a 19F MRI study in tumor-bearing mice, Magn Reson Imaging, 7 (1989) 475-485. 
[15] P. Gowland, P. Mansfield, Accurate measurement of T1 in vivo in less than 3 seconds using echo-planar imaging, Mag reson med, 30 (1993) 351-354.

[16] D. Zhao, L. Jiang, R.P. Mason, Measuring changes in tumor oxygenation, Methods Enzymol, 386 (2004) 378-418.

[17] B. Heurtault, P. Saulnier, B. Pech, J.E. Proust, J.P. Benoit, A novel phase inversionbased process for the preparation of lipid nanocarriers, Pharm Res, 19 (2002) 875-880.

[18] N.T. Huynh, C. Passirani, P. Saulnier, J.P. Benoit, Lipid nanocapsules: a new platform for nanomedicine, Int J Pharmaceut, 379 (2009) 201-209.

[19] E. Garcion, A. Lamprecht, B. Heurtault, A. Paillard, A. Aubert-Pouessel, B. Denizot, P. Menei, J.P. Benoit, A new generation of anticancer, drug-loaded, colloidal vectors reverses multidrug resistance in glioma and reduces tumor progression in rats, Mol Cancer Ther, 5 (2006) 1710-1722.

[20] A. Vonarbourg, C. Passirani, L. Desigaux, E. Allard, P. Saulnier, O. Lambert, J.P. Benoit, B. Pitard, The encapsulation of DNA molecules within biomimetic lipid nanocapsules, Biomaterials, 30 (2009) 3197-3204.

[21] E. Allard, F. Hindre, C. Passirani, L. Lemaire, N. Lepareur, N. Noiret, P. Menei, J.P. Benoit, 188Re-loaded lipid nanocapsules as a promising radiopharmaceutical carrier for internal radiotherapy of malignant gliomas, Eur J Nucl Med Mol Imaging, 35 (2008) 18381846.

[22] M. Srinivas, L.J. Cruz, F. Bonetto, A. Heerschap, C.G. Figdor, I.J.M. de Vries, Customizable, multi-functional fluorocarbon nanoparticles for quantitative in vivo imaging using (19)F MRI and optical imaging, Biomaterials, 31 (2010) 7070-7077.

[23] C. Vanpouille-Box, F. Lacoeuille, C. Belloche, N. Lepareur, L. Lemaire, J.J. LeJeune, J.P. Benoit, P. Menei, O.F. Couturier, E. Garcion, F. Hindre, Tumor eradication in rat glioma and bypass of immunosuppressive barriers using internal radiation with (188)Re-lipid nanocapsules, Biomaterials, 32 (2011) 6781-6790.

[24] R.H. Bobo, D.W. Laske, A. Akbasak, P.F. Morrison, R.L. Dedrick, E.H. Oldfield, Convection-enhanced delivery of macromolecules in the brain, Proc Natl Acad Sci U S A, 91 (1994) 2076-2080.

[25] C.O. Noble, M.T. Krauze, D.C. Drummond, Y. Yamashita, R. Saito, M.S. Berger, D.B. Kirpotin, K.S. Bankiewicz, J.W. Park, Novel nanoliposomal CPT-11 infused by convectionenhanced delivery in intracranial tumors: pharmacology and efficacy, Cancer Res, 66 (2006) 2801-2806.

[26] J. Benjamins, A. Gagna, E.H. Lucassen Reynders, Viscoelastic properties of triacylglycerol/water interfaces covered by proteins Colloids and Surfaces A, 114 (1996) 245254.

[27] H. Ohshima, Electrophoretic mobility of soft particles, Electrophoresis, 16 (1995) 13601363.

[28] H. Ohshima, On the General Expression for the Electrophoretic Mobility of a Soft Particle, J Colloid Interface Sci, 228 (2000) 190-193.

[29] G.E.C. Sims, T.J. Snape, A method for the estimation of polyethylene glycol in plasma protein fractions, Analytical Biochemistry, 107 (1980) 60-63.

[30] L. Lemaire, F. Franconi, J.P. Saint-Andre, V.G. Roullin, P. Jallet, J.J. Le Jeune, Highfield quantitative transverse relaxation time, magnetization transfer and apparent water diffusion in experimental rat brain tumour, NMR Biomed, 13 (2000) 116-123.

[31] E. Bourseau-Guilmain, L. Lemaire, A. Griveau, E. Hervouet, F. Vallette, F. Berger, P. Menei, J.P. Benoit, D. Wion, E. Garcion, In vitro expansion of human glioblastoma cells at non-physiological oxygen tension irreversibly alters subsequent in vivo aggressiveness and AC133 expression, International Journal of Oncology, 40 (2012) 1220-1229. 
[32] A. Vonarbourg, A. Sapin, L. Lemaire, F. Franconi, P. Menei, P. Jallet, J.J. Le Jeune, Characterization and detection of experimental rat gliomas using magnetic resonance imaging, Magma, 17 (2004) 133-139.

[33] F. Franconi, C. Chapon, J.J. Le Jeune, P. Richomme, L. Lemaire, Susceptibility gradient quantization by MRI signal response mapping (SIRMA) to dephaser, Medical Physics, 37 (2010) 877-884.

[34] B. Heurtault, P. Saulnier, B. Pech, J.E. Proust, J.P. Benoit, Physico-chemical stability of colloidal lipid particles, Biomaterials, 24 (2003) 4283-4300.

[35] X.B. Fan, J.N. River, A.S. Muresan, C. Popescu, M. Zamora, R.M. Culp, G.S. Karczmar, MRI of perfluorocarbon emulsion kinetics in rodent mammary tumours Physics in Medicine and Biology 51 (2006) 211-220.

[36] G.M. Lanza, K.D. Wallace, M.J. Scott, W.P. Cacheris, D.R. Abendschein, D.H. Christy, A.M. Sharkey, J.G. Miller, P.J. Gaffney, S.A. Wickline, A novel site-targeted ultrasonic contrast agent with broad biomedical application, Circulation, 94 (1996) 3334-3340.

[37] B. Heurtault, P. Saulnier, B. Pech, M.-C. Venier-Julienne, J. Proust, E., R. Phan-TanLuu, J.-P. Benoit, The influence of lipid nanocapsule composition on their size distribution, European Journal of Pharmaceutical Sciences 18 (2003) 55-61.

[38] B. Heurtault, P. Saulnier, B. Pech, J.E. Proust, J.P. Benoit, Properties of polyethylene glycol 660 12-hydroxy stearate at a triglyceride/water interface, Int J Pharmaceut, 242 (2002) $167-170$.

[39] A. Vonarbourg, P. Saulnier, C. Passirani, J.P. Benoit, Electrokinetic properties of noncharged lipid nanocapsules: influence of the dipolar distribution at the interface, Electrophoresis, 26 (2005) 2066-2075.

[40] I. Minkov, T. Ivanova, I. Panaiotov, J. Proust, P. Saulnier, Reorganization of lipid nanocapsules at air-water interface - Part 2. Properties of the formed surface film, Colloid Surface B, 44 (2005) 197-203.

[41] C. Diepart, B.F. Jordan, B. Gallez, A New EPR oximetry protocol to estimate the tissue oxygen consumption in vivo, Radiation Research, 172 (2009) 220-225.

[42] B.F. Jordan, G.O. Cron, B. Gallez, Rapid monitoring of oxygenation by $19 \mathrm{~F}$ magnetic resonance imaging: Simultaneous comparison with fluorescence quenching, Magnet Reson Med, 61 (2009) 634-638. 


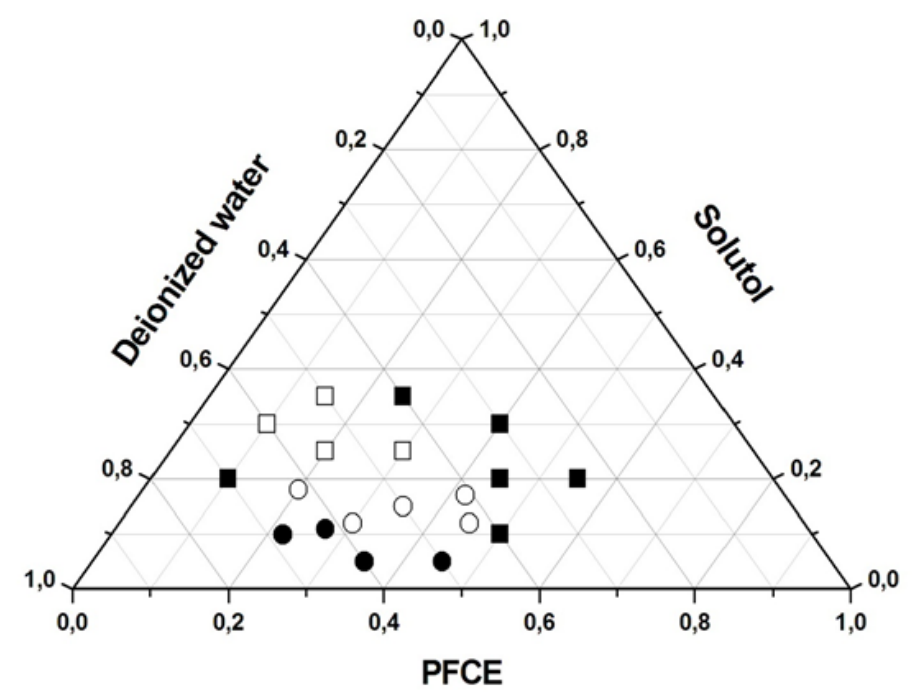

Figure 1. PFCE-Solutol-deionized water ternary phase diagram representing the influence of component weight proportions on the PFCE-LNC size properties.

The closed squares $(\mathbf{D})$ correspond to particles with Z-ave $>200-\mathrm{nm}$ and Pdl $>0.2$; the closed circles $(\bullet)$ to particles with Z-ave $>200-\mathrm{nm}$ and Pdl $<0.2$; the opened squares $(\square)$ to particles with $Z$-ave $<200 \mathrm{nnm}$ and $\mathrm{Pdl}>0.2$ and the opened circles $(O)$ to particles with Z-ave $<200-\mathrm{nm}$ and $\mathrm{Pdl}<0.2$. 


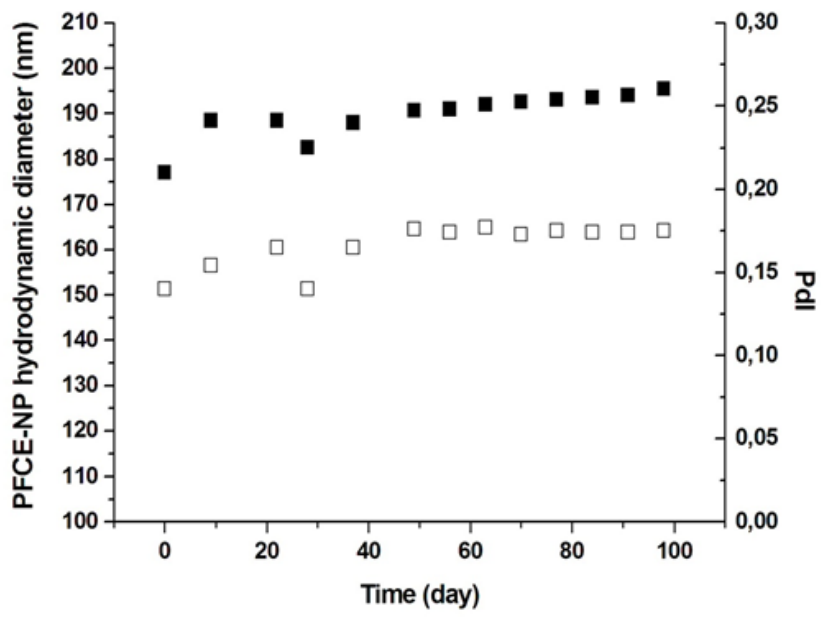

Figure 2. Size stability of PFCE-LNC as a function of time.

Assessment of the hydrodynamic diameter (Z-ave) ( $\square$ ) and Pdl ( $\square$ ) of PFCE-LNC as a function of time. The samples were stored at a temperature of $4^{\circ} \mathrm{C}$. 


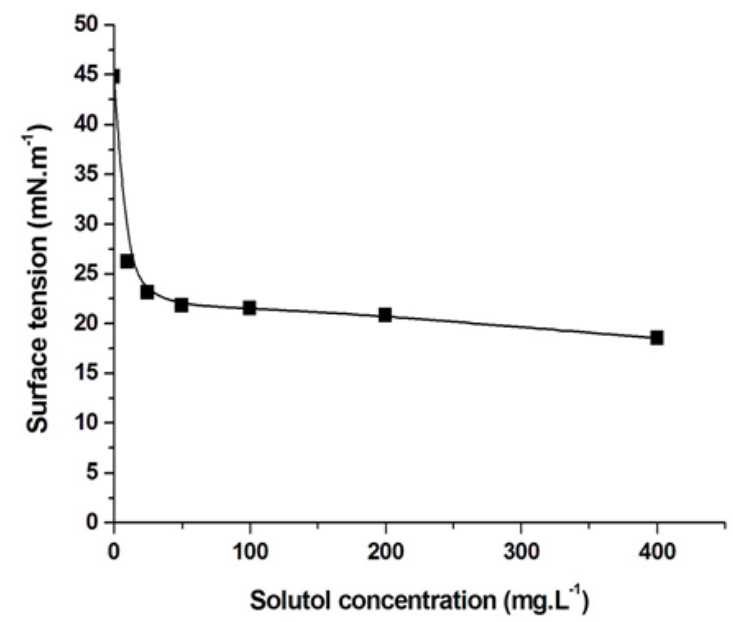

Figure 3. Evolution of the surface tension at the water - PFCE interface as a function of the solutol $\circledast$ HS 15 concentration in the water phase assessed using the pendant drop tensiometry.

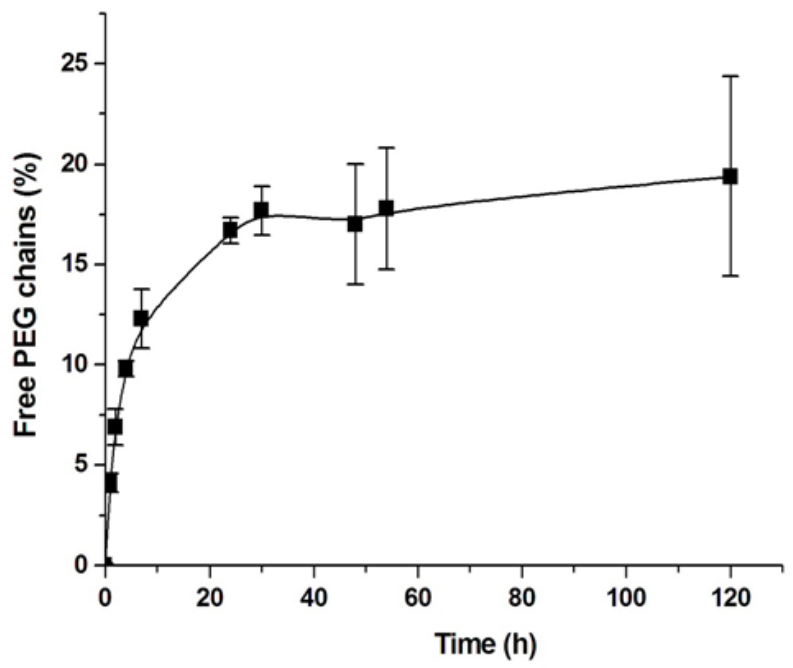

Figure 4. Quantification of free PEG chains present in the suspension of PFCE-LNC, as a function of the dialysis time $\left(M_{w C O}=50 \mathrm{kDa}\right)$. 


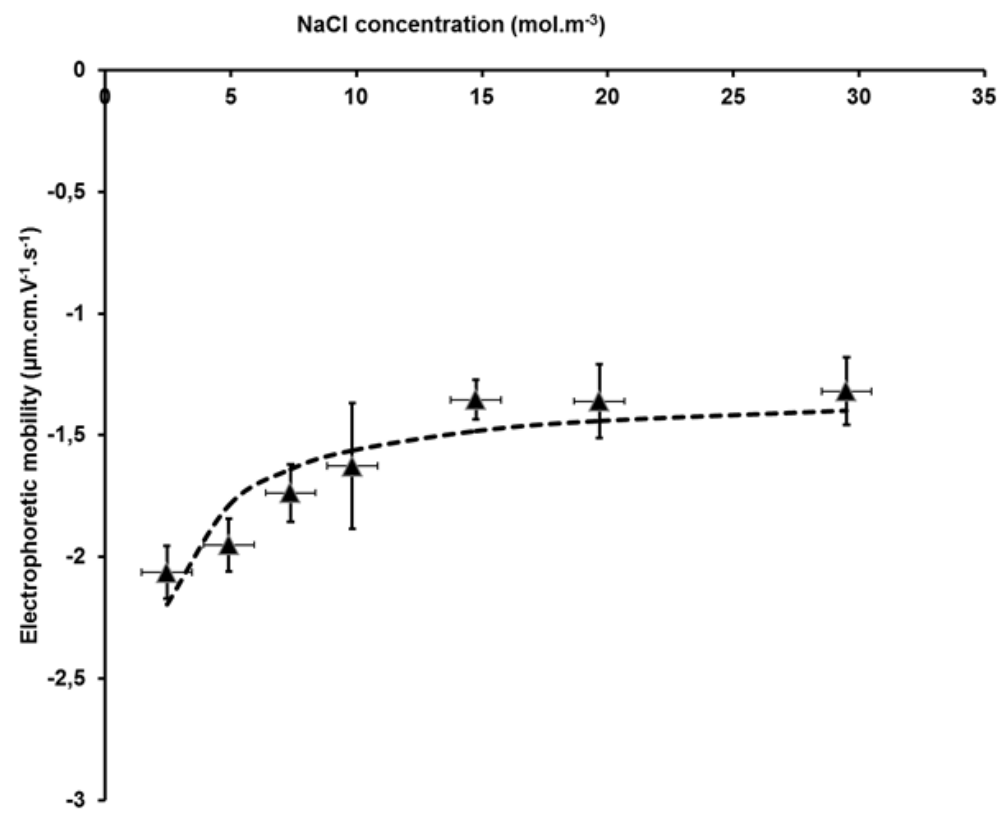

Figure 5. Measurement of PFCE-LNC electrophoretic mobility as a function of $\mathrm{NaCl}$ concentration ( $\mathbf{\square})$. Data were fitted using the Ohshima model (dilution by a factor 600) and the continuous line is drawn with $Z N=-0,67 \pm 0,21 \cdot 10^{-6} \mathrm{C} \cdot \mathrm{m}^{-3}$ and $1 / \lambda=3.5 \pm 1.0 \mathrm{~nm}$. 


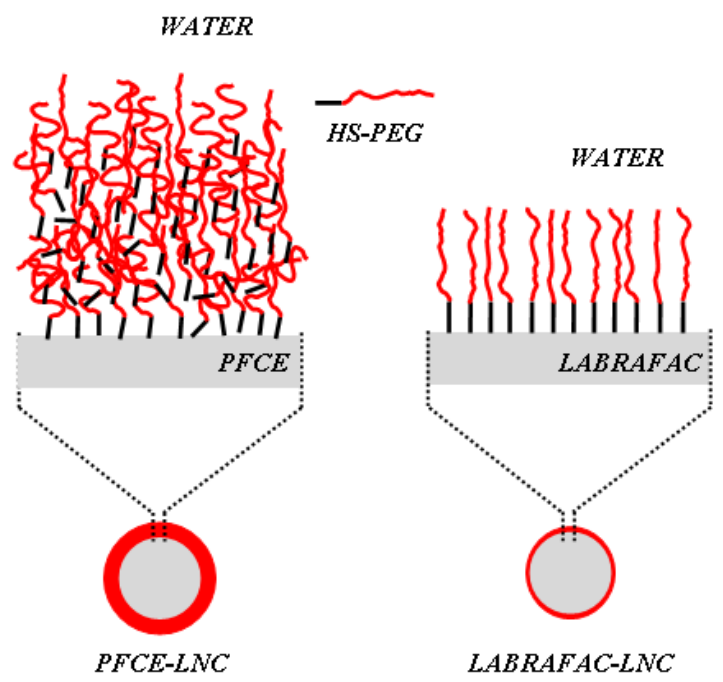

Figure 6. Schematic representation of the HS-PEG organization at the interface water/PFCE and at the interface water/labrafac. 


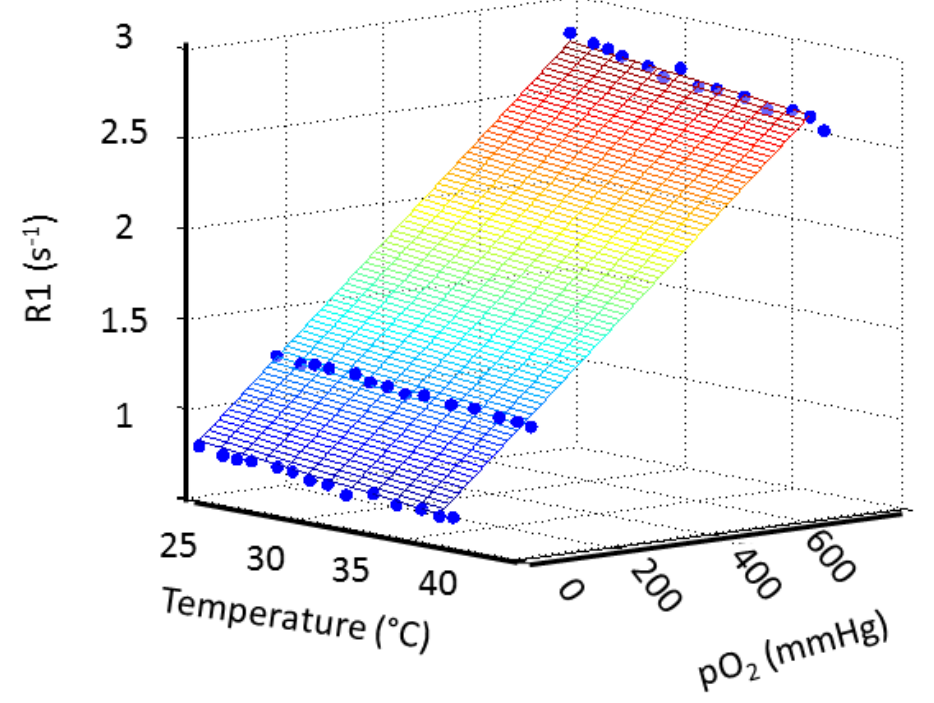

Figure 7. In vitro standard calibration curves of PFCE-LNC. The plot represents the R1 values measured for the PFCE-LNC as a function of the quantity of oxygen dissolved in the medium and for different temperatures ranging from 25 to $39^{\circ} \mathrm{C}$. 

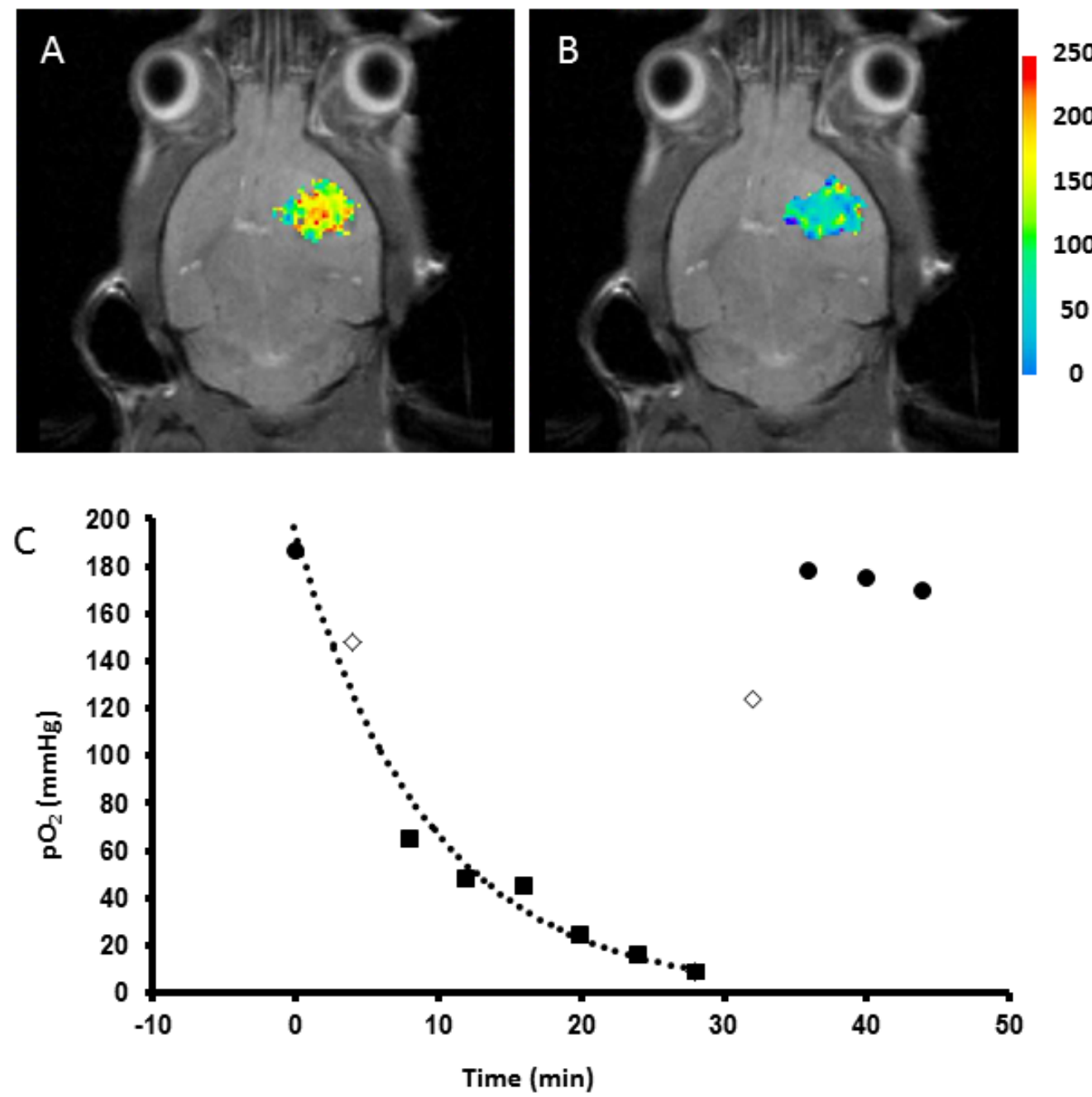

Figure 8. Assessment of a mouse brain tumor $\mathrm{pO}_{2}$ using fluorine MRI after stereotactic injection of $8 \mu \mathrm{L}$ of a suspension of PFCE-LNC.

The colored part of frames A \& B corresponds to the $\mathrm{pO} 2$ measurements performed when the animal was breathing pure oxygen or air, respectively. The gray part of the image corresponds to the standard anatomical proton image used as the background.

On frame $\mathrm{C}$, is presented the time course evolution of tumor $\mathrm{pO}_{2}$ when the animal was experiencing a hypoxic challenge. The closed circles $(\bullet)$ correspond to pO2 measurements performed when the animal was breathing pure oxygen, the closed squares ( $\boldsymbol{\square})$ air and the open diamonds $(0)$ correspond to a value measured when the gas was switched from oxygen to air. The dashed line corresponds to the exponential fit of the experimental data points acquired during the air phase leading to oxygen consumption constant $\mathrm{k}=0,16 \mathrm{~min}^{-1}$. 